Check for updates

Cite this: J. Mater. Chem. A, 2018, 6, 11521

Received 25th January 2018

Accepted 22nd May 2018

DOI: $10.1039 / \mathrm{c} 8 \mathrm{ta0} 0827 \mathrm{~b}$

rsc.li/materials-a

\section{Improved performance of binder-free zeolite $Y$ for low-temperature sorption heat storage $\uparrow$}

\begin{abstract}
Alenka Ristić, (D) *a Fabian Fischer, ${ }^{\mathrm{b}}$ Andreas Hauer ${ }^{\mathrm{b}}$ and Nataša Zabukovec Logar (D) ac
The sustainable generation of energy and low-energy consuming technologies are two main approaches to combat climate change and reduce carbon dioxide emissions. Sorption heat storage is part of the second approach. Therefore, adsorbents that achieve high energy storage density under the working conditions of the storage application are required. In this study, the hydrophilic properties of a granulated binder-free zeolite $\mathrm{NaY}$ were tailored with the aim of increasing its performance at a desorption temperature of $140{ }^{\circ} \mathrm{C}$ for mobile sorption heat storage. Top-down approaches, such as chemical treatment with the chelating agent $\mathrm{H}_{4}$ EDTA, treatment with the inorganic acid $\mathrm{HCl}$ and sequential ion exchange with acid treatment, were used in order to decrease the desorption temperature and optimize the lowtemperature heat storage density. All the modified samples showed a decrease in the desorption temperature from 10 to $30{ }^{\circ} \mathrm{C}$ compared to the parent sample; only the desorption temperature of the acid-treated $\mathrm{Mg}$-exchanged $\mathrm{NaY}$ sample increased. The effect of different treatments on the structural properties of the materials, including the generation of framework defects and mesoporosity was determined. The energy storage densities of the $\mathrm{NaY}$ and all the modified samples are considerably higher in comparison to the currently used adsorbent (NaMSX) in mobile sorption heat storage for lowtemperature industrial waste heat recovery.
\end{abstract}

\section{Introduction}

Thermal energy storage (TES) plays a key role in the more rational use of energy because it allows the decoupling of the production and demand for thermal energy. Recent research activities have been focused on the development of heat storage systems that would enable the efficient utilization of lowtemperature solar or waste heat for heating, cooling or drying applications. There are three main types of thermal energy storage systems: latent, sensible and thermochemical heat storage technologies. ${ }^{1,2}$ Latent heat storage uses the phase change enthalpy of phase-change materials for storage. Sensible heat storage is based on increasing or decreasing the temperature of a high heat capacity storage medium, thus storing and releasing heat. Thermochemical heat storage utilizes the reversible chemical reaction and/or sorption processes of gases in solids or liquids. ${ }^{2}$ This process usually consists of two phases. Under the influence of a heat supply, water is desorbed from the material and is then stored separately (closed system) or is dissipated into the environment (open system). This

${ }^{a}$ Department of Inorganic Chemistry and Technology, National Institute of Chemistry Slovenia, Hajdrihova 19, SI-1001 Ljubljana, Slovenia.E-mail: alenka.ristic@ki.si

${ }^{b}$ Bavarian Center for Applied Energy Research - ZAE Bayern, Walther-Meißner-Str.6, 85748 Garching, Germany

${ }^{c}$ University of Nova Gorica, Vipavska 13, 5000 Nova Gorica, Slovenia

$\dagger$ Electronic supplementary information (ESI) available. See DOI: $10.1039 / \mathrm{c} 8 \mathrm{ta} 00827 \mathrm{~b}$ endothermic phenomenon corresponds to the charging or activation of the storage material. When water is adsorbed onto the adsorbent, heat is released (an exothermic phenomenon referred to as the discharge or deactivation of a material). In comparison to latent or sensible heat storage, sorption energy storage achieves higher energy storage densities with negligible heat losses during the storage phase. In addition, sorption energy storage can also work as a heat pump, since it is able to deliver the thermal energy at temperatures above the charging temperature. ${ }^{3}$ Thus, it has the potential to make extensive use of solar thermal energy and low-temperature industrial waste heat (IWH) (e.g. the food, paper, and washing industries), leading to a low carbon energy society.

Zeolites have an increasingly important role in many sustainable processes; particularly, in the last decade they have been preferred as highly hydrophilic adsorbents for sorption heat storage with water as a fluid medium. The main criteria for the selection of a proper adsorbent for sorption thermal energy storage are high sorption capacity, a low desorption temperature and a high-temperature level of released heat., ${ }^{4,5}$ The hydrophilicity of zeolites is an important factor for the application of these adsorbents in solar or waste heat driven systems and is usually dependent on their $\mathrm{Al}$ content, i.e. the Si/Al molar ratio of the zeolite framework, the framework structure type, and the related exchangeable extra-framework cation sites. ${ }^{6}$ The water sorption capacity depends on the type of extra-framework cations as well as the degree of ion-exchange and decreases 
from $\mathrm{Li}$ to Cs due to the decrease in the free volume of the large cavities of zeolites as a result of the increased cation diameter. ${ }^{7}$ Jänchen systematically studied the effect of cations on water sorption uptake. ${ }^{8}$ It was revealed that zeolites exchanged with smaller cations (e.g. $\mathrm{Mg}$ ) have a higher water sorption capacity due to the enlargement of the pore volume of the exchanged zeolite. ${ }^{9,10}$ The high affinity to water of zeolites under low partial pressure influences the temperature of desorption. High desorption temperatures $\left(>200{ }^{\circ} \mathrm{C}\right)$ are a consequence of the strong interaction between the charged frameworks and the water molecules. Recently, the manufacturing of granulated binder-free zeolites ${ }^{\mathbf{1 1}}$ has been enabled to tailor the hydrophilic character of the storage materials. Granulated or shaped zeolites are advantageous for use in open sorption storage systems. The water sorption capacity of binder-free zeolites (e.g. shaped bodies mainly containing zeolites) has been determined to be higher compared to those of zeolites containing binders of 14\% for zeolite A and 16\% for zeolite X. Both open and closed storage tests have shown comparable adsorption capacities and specific energies for the binder-free zeolites. ${ }^{12}$ The main drawback is their high desorption temperature, which can be overcome by reducing their strong hydrophilicity. Less hydrophilic zeolites can be obtained by changing their chemical composition with several post-synthesis modifications, for example dealumination $^{\mathbf{1 3}}$ and, recently, by the functionalization of zeolites through the chemisorption of organosilanes. ${ }^{\mathbf{1 4}}$ Dealumination can be accomplished using many techniques, from steaming treatments to acid leaching and chemical treatments. ${ }^{15-20}$ Dealuminated zeolites contain less $\mathrm{Al}$ (a higher Si/Al molar ratio) and correspondingly fewer strong adsorption sites in the cavities, and thus, less water is less strongly bonded. ${ }^{21}$ The removal of $\mathrm{Al}$ atoms from the framework leads to the formation of materials with bimodal porosity and/or to a change in framework compositions. ${ }^{22}$ It should be mentioned that the later changes are generally unpredictable and difficult to control. The extraction of $\mathrm{Al}$ cations from tetrahedral positions in the framework creates defects. In many cases the enhanced textural properties were the only achieved benefits. The secondary mesoporosity, which significantly enhances the accessibility of active sites, depends on the type of dealumination procedure. ${ }^{13}$ Dealumination with citric acid, for example, prevented the crystalline structure from collapse, created some defects in the framework and did not produce any mesoporosity. ${ }^{23}$

Technologies to use waste heat from industries can be used on-site if the IWH generation and heat demand are at the same location. In cases where a district heating grid is not feasible, the transportation of industrial waste heat from the heat source to the heat demand (a mobile TES or M-TES) can be an alternative. ${ }^{24}$ For example, an M-TES based on an open sorption system with 14 tons of zeolite NaMSX (13X) with a binder was used to recover the IWH from an incineration plant located 7 $\mathrm{km}$ from the industrial drying process (heat demand) and achieved an energy storage capacity of $2 \mathrm{MW} \mathrm{h}$ (without sensible heat) resulting in an energy storage density of $143 \mathrm{~W} \mathrm{~h} \mathrm{~kg}^{-1}$ with a desorption temperature of $135{ }^{\circ} \mathrm{C} .{ }^{25}$ Increasing the gravimetric energy storage density for the M-TES is particularly essential, since the maximum truck load weight limits the amount of storage material. To the best of our knowledge, this is the only case of M-TES application where an open sorption system based on a zeolite is used.

Furthermore, the use of zeolites for applications in the middle temperature range $\left(120-150^{\circ} \mathrm{C}\right)$ is very rare. Yu reported a performance map (energy storage density versus the desorption temperature) of materials for sorption heat storage, showing a blank area for zeolites at the desorption temperatures from 120 to $150{ }^{\circ} \mathrm{C}^{26}$ Namely, the reported zeolites performed at the desorption temperatures above $150{ }^{\circ} \mathrm{C}$.

Here we present for the first time the use of commercial granulated binder-free zeolite $\mathrm{NaY}$ as the adsorbent for mobile sorption heat storage and the post-synthesis modification of this zeolite in order to decrease the desorption temperature and preserve the energy storage density by tailoring its hydrophilic properties. We have studied the effect of $\mathrm{HCl}$ and $\mathrm{H}_{4}$ EDTA treatments, as well as the impact of sequential ion-exchange acid treatment on the material storage performance, i.e. on the desorption temperature and energy storage density. The structural properties responsible for the sorption properties of these adsorbents were determined. The water sorption properties of the parent sample $\mathrm{NaY}$ and post-synthesis modified samples were studied in detail and compared to those of granulated zeolite NaMSX with a binder already used in mobile sorption heat storage for low-temperature industrial waste heat recovery. ${ }^{25}$

\section{Experimental section}

\section{Material preparation}

Binder-free granulated zeolite NaY (parent sample) was supplied by CWK (Bad Köstritz, Germany). $\mathrm{HCl}$ (37\%, Merck) and $\mathrm{H}_{4}$ EDTA ( $>99 \%$, ABCR GMBH) were used for the preparation of solutions with different concentrations. $\mathrm{Mg}\left(\mathrm{NO}_{3}\right)_{2} \cdot 6 \mathrm{H}_{2} \mathrm{O}$ (99\%, VWR Chemicals) was used for the ion exchange treatment.

The modified samples were prepared using one-step and two-step procedures (see Table 1).

One-step procedures. $2 \mathrm{~g}$ of granulated binder-free zeolite $\mathrm{NaY}$ was immersed in $50 \mathrm{~mL}$ of $\mathrm{HCl}$ with different concentrations $(0.025-0.1 \mathrm{M})$ at $100{ }^{\circ} \mathrm{C}$ for 1 hour or at room temperature (RT) for 5 days. Then the samples were filtered, washed several

Table 1 Preparation conditions for the post-synthesis modifications of granulated binder-free $\mathrm{NaY}$

\begin{tabular}{lllll}
\hline Samples & Treatment & $\begin{array}{l}\text { Temperature } \\
\left({ }^{\circ} \mathrm{C}\right)\end{array}$ & Time $(\mathrm{h})$ & Step \\
\hline Parent NaY & - & - & - & - \\
$0025 \mathrm{HCl}$ & $0.025 \mathrm{M} \mathrm{HCl}$ & 100 & 1 & One \\
$005 \mathrm{HCl}$ & $0.05 \mathrm{M} \mathrm{HCl}$ & 100 & 1 & One \\
$01 \mathrm{HCl}$ & $0.1 \mathrm{M} \mathrm{HCl}$ & 100 & 1 & One \\
005HCl-RT & $0.05 \mathrm{HCl}$ & $\mathrm{RT}$ & 120 & One \\
005EDTA & $0.05 \mathrm{M} \mathrm{H} \mathrm{HDTA}_{4} \mathrm{ED}$ & 100 & 20 & One \\
MgNaY-0025HCl & $1{\mathrm{M} \mathrm{Mg}\left(\mathrm{NO}_{3}\right)_{2}}$ & 85 & 2 & Two \\
& $0.025 \mathrm{M} \mathrm{HCl}$ & 100 & 1 &
\end{tabular}


times with distilled water and $96 \%$ ethanol and dried at $65{ }^{\circ} \mathrm{C}$ for $2 \mathrm{~h}$. The acid-treated samples were denoted as $0025 \mathrm{HCl}$, $005 \mathrm{HCl}, 01 \mathrm{HCl}$ and $005 \mathrm{HCl}-\mathrm{RT}$. The same amount of parent sample was used for the post-synthesis modification with the chelating agent $\mathrm{H}_{4}$ EDTA. The binder-free zeolite $\mathrm{NaY}$ was treated with $0.05 \mathrm{M} \mathrm{H}_{4}$ EDTA at $100{ }^{\circ} \mathrm{C}$ for 20 hours. Then the sample was filtered, washed several times with distilled water and $96 \%$ ethanol and dried at $65{ }^{\circ} \mathrm{C}$ for $2 \mathrm{~h}$. This sample was denoted as 005EDTA.

Two-step procedure. The last sample was prepared using a sequential procedure of $\mathrm{Mg}$-exchange and acid treatment in $0.025 \mathrm{HCl}$ at $100{ }^{\circ} \mathrm{C}$ for 1 hour. $2 \mathrm{~g}$ of the parent sample NaY was added to $1 \mathrm{M} \mathrm{Mg}\left(\mathrm{NO}_{3}\right)_{2}$ and stirred at $85{ }^{\circ} \mathrm{C}$ for 2 hours. Then the sample was filtered, washed several times with distilled water and $96 \%$ ethanol and dried at $65{ }^{\circ} \mathrm{C}$ for $2 \mathrm{~h}$. The $\mathrm{Mg}$-exchanged sample was then acid-treated in $0.025 \mathrm{M}$ $\mathrm{HCl}$ at $100{ }^{\circ} \mathrm{C}$ for 1 hour; the sample was filtered, washed several times with distilled water and $96 \%$ ethanol and dried at $65{ }^{\circ} \mathrm{C}$ for $2 \mathrm{~h}$. This sample was denoted as MgNaY$0025 \mathrm{HCl}$.

\section{Structural characterization}

X-ray powder diffraction (XRD) patterns were recorded using a PANalytical X'Pert PRO high-resolution diffractometer with $\mathrm{Cu}$ $\mathrm{K}_{\alpha 1}$ radiation $(\lambda=1.5406 \AA)$ in the $2 \theta$ range from 5 to $50^{\circ}$ with the step of $0.033^{\circ}$ per $100 \mathrm{~s}$ using a fully opened X'Celerator detector. The degree of crystallinity was estimated by comparing the area of the diffraction peaks in the $2 \theta$ range from 20 to $30^{\circ}$ to that of the same peaks of the reference NaY sample. To compare the relative crystallinity of the modified samples, the standard method described in the ASTM D3906-03 was followed. ${ }^{27}$ The crystallinity of all the samples was compared to that of the parent sample NaY, which was set to $100 \%$. The XRD patterns of the cycled samples were obtained on a Si slice due to the small amount of the samples using a PANalytical X'Pert PRO highresolution diffractometer with $\mathrm{Cu} \mathrm{K}_{\alpha 1}$ radiation $(\lambda=1.5406 \AA)$ in the $2 \theta$ range from 5 to $50^{\circ}$ with the step of $0.033^{\circ}$ per $100 \mathrm{~s}$ using a fully opened X'Celerator detector. The samples after 20 cycles were compared to the samples before the cycling test, which were set to $100 \%$. Elemental analysis of the samples was performed by energy dispersive X-ray analysis using an INCA Energy system attached to a Zeiss Supra ${ }^{\mathrm{TM}}$ 3VP microscope within a detection limit of $0.1 \%$. Scanning electron micrographs (SEMs) were taken on a Zeiss Supra ${ }^{\mathrm{TM}} 3 \mathrm{VP}$ electron microscope. Nitrogen sorption measurements of the granulated samples were performed on a Tristar 3000 volumetric adsorption analyser (Micromeritics) at $77 \mathrm{~K}$. The BET specific surface area, $S_{\mathrm{BET}}$, was calculated using the adsorption branch of the isotherm in a relative pressure $\left(p / p_{0}\right)$ range between 0.01 and $0.1 .^{28}$ The total pore volume $\left(V_{\text {tot }}\right)$ was estimated from the amount adsorbed at a relative pressure of 0.95 . The external surface area $\left(S_{\text {ext }}\right)$ and micropore volume $\left(V_{\text {mic }}\right)$ were determined using the $t$-plot method at a relative pressure $\left(p / p_{0}\right)$ range from 0.05 to $0.35 .^{29}$ Prior to TG measurements, the samples were exposed to a saturated solution of ammonium chloride (relative humidity $\sim 75 \%$ ) at room temperature for 7 days in order to prepare fully hydrated samples. Thermogravimetric investigation was performed using a Q5000IR (TA Instruments). For all measurements, the samples were heated in a stream of air at a heating rate of $10{ }^{\circ} \mathrm{C} \mathrm{min}^{-1}$. The temperature of the maximum $\left(T_{\text {peak }}\right)$ is considered as the desorption temperature.

\section{Water sorption characterization}

Adsorption isotherms. The adsorption isotherms of water at $25{ }^{\circ} \mathrm{C}$ were measured via the volumetric measurement method using a BELSORP Aqua ${ }^{3}$ from Bel Japan. About $200 \mathrm{mg}$ of the sample was dried under vacuum with a final pressure of $p<1 \times$ $10^{-4} \mathrm{kPa}$ at $350{ }^{\circ} \mathrm{C}$ for $8 \mathrm{~h}$ to remove the water molecules. Then the adsorption isotherm was measured using the BELSORP Aqua $^{3}$ by dosing water into the sample cell and determining the pressure decrease at equilibrium. Water sorption analysis was performed using an IGA-100 gravimetric analyzer (Hiden Isochema Ltd.). Water sorption isotherms were obtained at $25{ }^{\circ} \mathrm{C}$ in the relative pressure $p / p_{0}$ range from 0 to 0.8 . Prior to measurements, the samples were degassed at $350{ }^{\circ} \mathrm{C}$ to a constant weight overnight.

Adsorption isobars. The adsorption isobars of water were measured using a Rubotherm magnetic suspension balance in combination with an automatic flow gas and water vapour dosing system. The dry sample mass was obtained by degassing the sample at $350{ }^{\circ} \mathrm{C}$ until the mass change was below $\pm 20 \mu \mathrm{g}$ within $20 \mathrm{~min}$. Then the heater was switched off. As soon as the temperature of the sample was $50{ }^{\circ} \mathrm{C}$ and the mass change was within $60 \mathrm{~min}< \pm 20 \mu \mathrm{g}$, the displayed mass was used as the dry mass of the sample. The adsorption isobar measurements were performed in a gas flow with a constant water vapour pressure of $1.23 \mathrm{kPa}$, except for the NaMSX sample, which was measured at $1.80 \mathrm{kPa}$. As the carrier gas, $\mathrm{N}_{2}$ was used (Nitrogen 5.0) with an absolute pressure of $100 \mathrm{kPa}$. The sorption measurements started at a sample temperature of $150{ }^{\circ} \mathrm{C}$ and continued stepwise until a temperature of $22{ }^{\circ} \mathrm{C}$ (adsorption). Then the temperature was raised again stepwise to $150{ }^{\circ} \mathrm{C}$ and the sorption equilibrium was detected in the same steps (desorption). At each step, the sorption equilibrium was awaited (mass change within $60 \mathrm{~min}< \pm 30 \mu \mathrm{g}$ ).

Calculating the heat of adsorption. The heat of adsorption was calculated using the theory of Dubinin. ${ }^{30}$ First, the adsorption equilibrium data of each sample obtained using the Rubotherm balance were plotted as the so-called characteristic curve (adsorbed volume $W_{\text {ads }}$ as a function of the adsorption potential $\Delta F$ ). The adsorbed volume $W_{\text {ads }}$ is defined as the quotient of the water uptake $X_{\mathrm{S}}$ and the temperature-dependent density of the adsorbed water $\rho_{\text {ads }}$ :

$$
W_{\mathrm{ads}}=\frac{X_{\mathrm{S}}}{\rho_{\mathrm{ads}}}
$$

The adsorption potential $\Delta F$ is defined as:

$$
\Delta F=\frac{R}{M_{\mathrm{ads}}} T \ln \frac{p_{\mathrm{S}}(T)}{p}
$$


For calculating the adsorption potential $\Delta F$, the universal gas constant $R$, the molar mass of the adsorbate $M_{\text {ads }}$, the temperature $T$, the saturation pressure $p_{\mathrm{S}}$ and the vapour partial pressure $p$ have to be known.

For calculating the temperature-dependent density of the adsorbed water $\rho_{\text {ads }}$, the density model of Hauer was used with $T_{0}=293.15 \mathrm{~K}$ and $\rho_{\text {ads }}\left(T_{0}\right)=0.9997 \mathrm{~g} \mathrm{~cm}^{-3}:^{30}$

$$
\rho_{\mathrm{ads}}=\rho_{\mathrm{ads}}\left(T_{0}\right)\left[1-3.781 \times 10^{-4} \mathrm{~K}^{-1}\left(T-T_{0}\right)\right]
$$

The data of each inverse characteristic curve as $W_{\text {ads }}=$ $W_{\text {ads }}(\Delta F)$ were mathematically described using a rational function. These functions were used for calculating the differential enthalpy of adsorption $\Delta h_{\mathrm{ads}}:^{31}$

$$
\Delta h_{\mathrm{ads}}=\Delta h_{\mathrm{v}}+\Delta F-\left.T \alpha W \frac{\delta \Delta F}{\delta W}\right|_{T}
$$

In eqn (4), the first term $\Delta h_{\mathrm{v}}$ denotes the enthalpy of vaporization, the second term $\Delta F$ denotes the adsorption potential, while the last term denotes the change in entropy upon adsorption. By integrating the differential enthalpy of adsorption $\Delta h_{\text {ads }}$ from $X_{\mathrm{S} \text {,des }}$ to $X_{\mathrm{S} \text {,ads }}$, we obtain the integral heat of adsorption $q_{\text {ads }}$, which is indicated as the heat storage density in $\mathrm{kJ}$ or $\mathrm{W} \mathrm{h}$ per unit of adsorbent mass:

$$
q_{\text {ads }}=\int_{X_{\mathrm{S}, \mathrm{des}}}^{X_{\mathrm{S}, \mathrm{dds}}} \Delta h_{\mathrm{ads}} \mathrm{d} X_{\mathrm{S}}
$$

The value of $X_{\mathrm{S}, \mathrm{des}}$ corresponds to the water uptake at equilibrium after desorption and the value of $X_{\mathrm{S} \text {,ads }}$ corresponds to the water uptake after adsorption. All the samples were evaluated at a charging/desorption temperature of $140{ }^{\circ} \mathrm{C}$ and a discharging/adsorption temperature of $40{ }^{\circ} \mathrm{C}$. The water vapour pressure during the charging and discharging of the samples was set to $1.23 \mathrm{kPa}$ (a dew point temperature of $10^{\circ} \mathrm{C}$ ). In addition to this basic scenario, the heat of adsorption of the samples was evaluated under the working conditions of the mobile sorption heat storage: ${ }^{25}$ a charging temperature of $135{ }^{\circ} \mathrm{C}$ at a water vapour pressure of $1.23 \mathrm{kPa}$ and a discharging temperature of $55{ }^{\circ} \mathrm{C}$ at a water vapour pressure of $5.63 \mathrm{kPa}$ (a dew point temperature of $35^{\circ} \mathrm{C}$ ).

Cyclic hydrothermal stability. The hydrothermal stability of the zeolite samples was also determined using the Rubotherm balance. The samples were subjected to 20 adsorption/ desorption cycles between temperatures of $40{ }^{\circ} \mathrm{C}$ and $140{ }^{\circ} \mathrm{C}$ at a constant water vapour pressure of $1.23 \mathrm{kPa}$. By comparing the water uptakes of the samples at a temperature of $40{ }^{\circ} \mathrm{C}$ and a water vapour pressure of $1.23 \mathrm{kPa}$ before and after cycling, the hydrothermal stability was evaluated. The percentage reduction is calculated as follows: (uptake before cycling - uptake after cycling)/uptake before cycling $\times 100 \%$.

Adsorption kinetics. The charging kinetics of the samples was examined using the Rubotherm balance under a dynamic $\mathrm{N}_{2}$ gas flow with an absolute pressure of $100 \mathrm{kPa}$, a flow rate of $400 \mathrm{~mL} \mathrm{~min}^{-1}$ and a constant water vapour pressure of $1.23 \mathrm{kPa}$. As soon as the conditions of the humidified gas flow and the sample temperature $\left(40{ }^{\circ} \mathrm{C}\right)$ were constant, the valve to the sample chamber was opened and the dry sample started to adsorb water. At this moment, the time counting started.

\section{Results and discussion}

\section{Structural properties}

Post-synthesis treatments such as chemical treatment with the chelating agent $\mathrm{H}_{4}$ EDTA, treatment with the inorganic acid $\mathrm{HCl}$ and sequential Mg-exchange with acid treatment were used (see Table 1) to modify the hydrophilic properties of a commercially available granulated binder-free zeolite NaY. The crystallinity of the investigated samples was monitored using X-ray powder diffraction. The XRD patterns (Fig. 1) of the samples modified using different post-synthesis treatments show highly crystalline modified materials, indicating that these mild treatment procedures were not destructive to the zeolite structure. The relative crystallinity (see Table 2 ) gradually decreased with the increase in the $\mathrm{HCl}$ concentration under the same preparation conditions, meaning that the crystalline structure was partially destroyed, ${ }^{32}$ but not by more than $7 \%$. It can be observed that longer acid treatment caused a lower crystallinity.

The lowest crystallinity $(89 \%)$ can be observed for the $005 \mathrm{HCl}-\mathrm{RT}$ sample, which was treated for a longer time in $\mathrm{HCl}$ solution at room temperature (RT). This is consistent with the studies performed by Verboekend et al., where it was shown that the amorphous material could be formed during the acid treatment. ${ }^{32}$ Two-step modification, e.g. the sequential $\mathrm{Mg}$ exchanged and acid-treated sample, also shows a lower (90\%) relative crystallinity. On the other hand, an increase in crystallinity was only detected in the $0025 \mathrm{HCl}$ sample.

The Si/Al molar ratio of the modified samples is shown in Table 2. Rather small differences were observed for the acidtreated samples, regardless of the concentration of the acid used. For example, treatment in $0025 \mathrm{M} \mathrm{HCl}$ caused a slight decrease in the $\mathrm{Si} / \mathrm{Al}$ molar ratio probably due to dissolution of the impurities, which remained after the preparation of the

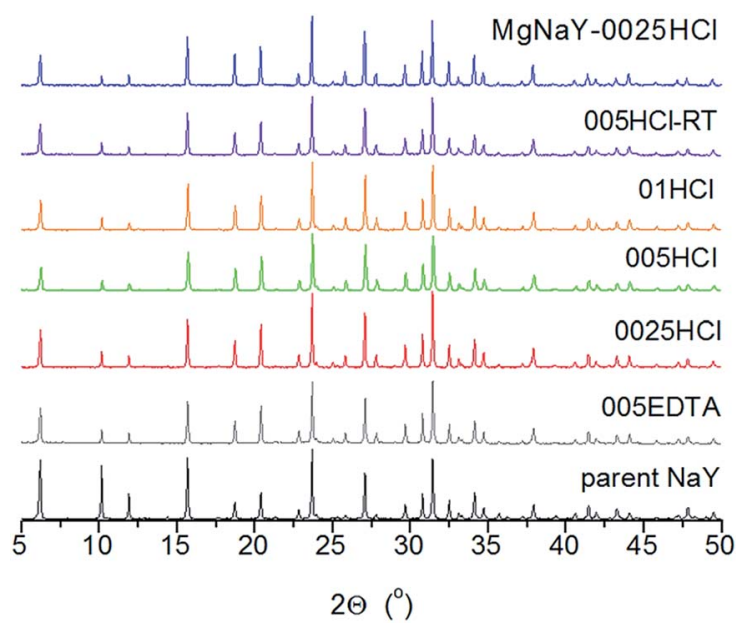

Fig. 1 XRD patterns of the parent sample $\mathrm{NaY}$ (black) and the modified samples: $0025 \mathrm{HCl}$ (red), $0.05 \mathrm{HCl}$ (green), $01 \mathrm{HCl}$ (orange), $005 \mathrm{HCl}-\mathrm{RT}$ (violet), 005EDTA (gray) and $\mathrm{MgNaY}-0025 \mathrm{HCl}$ (blue). 
Table 2 Relative crystallinity, Si/Al molar ratio and desorption temperature of the parent $\mathrm{NaY}$ and modified samples

\begin{tabular}{llll}
\hline Samples & $\begin{array}{l}\text { Relative crystallinity } \\
(\%)\end{array}$ & $\begin{array}{l}\text { Si/Al molar } \\
\text { ratio }\end{array}$ & $T_{\text {peak }}\left({ }^{\circ} \mathrm{C}\right)$ \\
\hline Parent NaY & 100 & 3.0 & 102 \\
0025HCl & 103 & 2.9 & 70 \\
005HCl & 95 & 3.1 & 84 \\
01HCl & 93 & 3.0 & 90 \\
005HCl-RT & 89 & 3.0 & 83 \\
005EDTA & 96 & 4.3 & 40,84 \\
MgNaY-0025HCl & 90 & 2.9 & 102,159
\end{tabular}

zeolite. Sachse et al. reported that the mild acid treatment of zeolite NaY slightly altered its chemical composition. ${ }^{23} \mathrm{Chem}-$ ical treatment with the chelating agent $\mathrm{H}_{4}$ EDTA increased the $\mathrm{Si} / \mathrm{Al}$ molar ratio, indicating the removal of aluminium from the framework. The lowest Si/Al molar ratio was determined for the $0025 \mathrm{HCl}$ sample and the MgNaY-0025HCl sample.

It can be seen from Fig. 2 that the post-synthesis modifications increase the amount of water in the adsorbents, most probably due to the presence of additional defects in the framework and the mesopores. Desorption is shifted to a lower temperature, except for the Mg-exchanged acid-treated sample (Fig. 2).

The desorption temperatures were determined from the DTG curves for these samples and are listed in Table 2. The DTG curves show one water loss for the acid-treated samples, while 005EDTA and the two-step treated sample MgNaY-0025HCl show two water losses. The desorption of water from the MgNaY-0025HCl sample was complete at a higher temperature than that of the parent sample, due to the presence of $\mathrm{Mg}$ cations. $^{8,10}$ The DTG curve of this sample indicates two adsorption sites: the first one is situated at the Na cations and the second one at the $\mathrm{Mg}$ cations. Water interacts more strongly with the $\mathrm{Mg}$ cations, and thus a higher temperature is needed to remove the water.

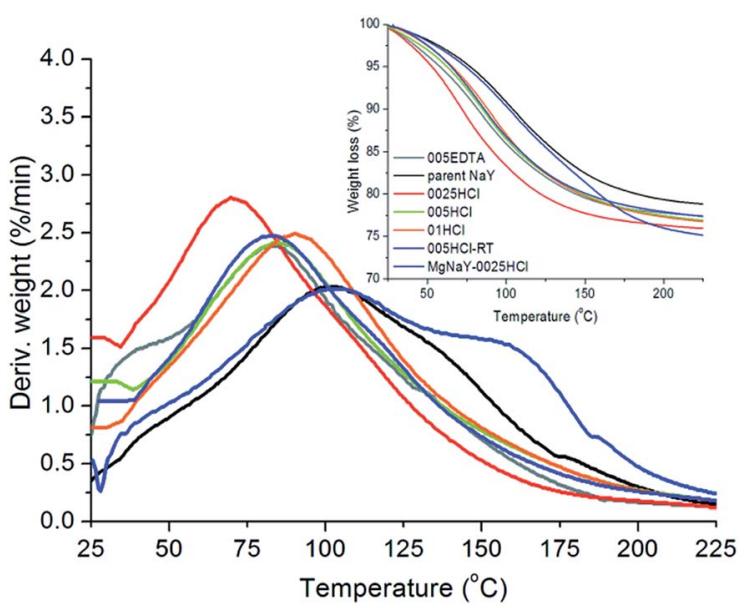

Fig. 2 DTG curves (inset: TG curves) of the parent sample NaY and the modified samples.
The SEM images of all the samples are presented in Fig. 3. The particle size of the modified zeolites is estimated, demonstrating agglomerates with an average particle size of 0.5 to 1 $\mu \mathrm{m}$, regardless of the modification procedure. No drastic changes in the particles after treatments are evident although the determined decrease in the relative crystallinity indicates a partial dissolution of the zeolite crystals during their treatment in the acidic solution. ${ }^{33,34}$ All the images show two different morphologies: prismatic crystals of zeolite $\mathrm{NaY}$ and the non-defined shape of small particles, which both belong to zeolite NaY according to Fig. 1. This observation is in agreement with the literature. ${ }^{11}$

The textural properties of the parent $\mathrm{NaY}$ and modified samples are presented in Table 3. It can be seen that acid treatments did not lead to significant structural degradation, which is in accordance with the determined relative crystallinity. Chemical treatment using $0.05 \mathrm{M} \mathrm{H}_{4}$ EDTA caused the preparation of the material with a larger total pore volume and a specific surface area and external area, indicating the introduction of secondary mesopores into this sample. ${ }^{13}$ This is supported by the observation that the micropore volume of the modified samples was decreased and the mesopore volume was slightly increased for the acid treated samples, while the $\mathrm{H}_{4}$ EDTA treated sample showed the highest increase of the mesoporous volume of all samples. According to Fig. S1, $\dagger$ mesoporosity was observed for this sample. Only minor mesoporosity was observed for the $\mathrm{HCl}$ treated samples. ${ }^{35}$ It can be seen that the applied acid concentrations influenced the reduction of the micropore volume (Table 3). Aguado showed that the decreasing micropore volume throughout the postsynthesis treatment was a direct consequence of the formation of mesoporosity in a microporous solid. ${ }^{36}$ Verboekend reported that a Si/Al molar ratio of roughly 4 for the zeolite $\mathrm{NH}_{4}-\mathrm{Y}$ should be attained in order to introduce substantial mesoporosity. ${ }^{32}$ In our study similar observation of the formation of mesopores was found for the 005EDTA sample with a Si/Al molar ratio of 4.3 .
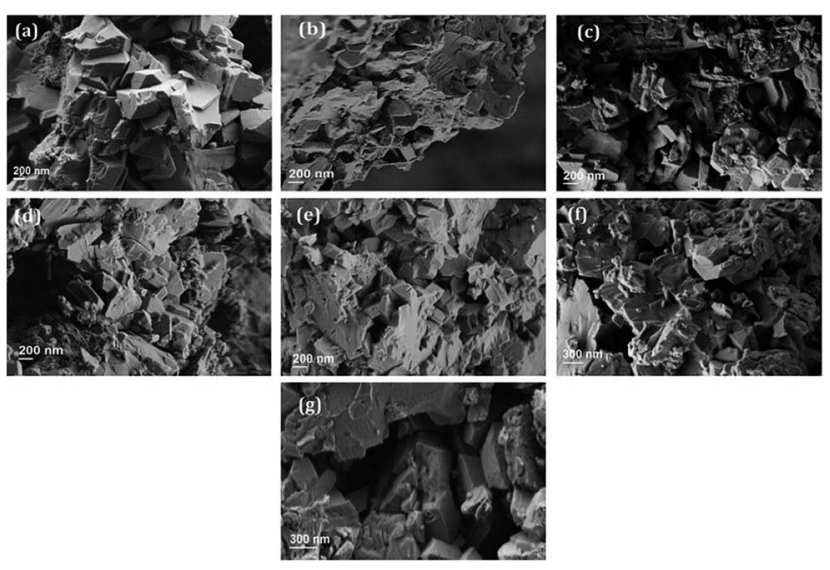

Fig. 3 SEM images of the parent and modified samples: (a) parent sample $\mathrm{NaY}$, (b) $0025 \mathrm{HCl}$, (c) $005 \mathrm{HCl}$, (d) $01 \mathrm{HCl}$, (e) $005 \mathrm{HCl}-\mathrm{RT}$, (f) 005EDTA and (g) MgNaY-0025 HCl. 
Table 3 Textural properties of the parent $\mathrm{NaY}$ and the modified samples ${ }^{a}$

\begin{tabular}{|c|c|c|c|c|c|}
\hline Sample & $S_{\mathrm{BET}}\left(\mathrm{m}^{2} \mathrm{~g}^{-1}\right)$ & $V_{\text {tot }}\left(\mathrm{cm}^{3} \mathrm{~g}^{-1}\right)$ & $V_{\text {mic }}\left(\mathrm{cm}^{3} \mathrm{~g}^{-1}\right)$ & $V_{\text {me }}\left(\mathrm{cm}^{3} \mathrm{~g}^{-1}\right)$ & $S_{\text {ext }}\left(\mathrm{m}^{2} \mathrm{~g}^{-1}\right)$ \\
\hline Parent NaY & 678 & 0.345 & 0.313 & 0.032 & 40 \\
\hline $0025 \mathrm{HCl}$ & 886 & 0.344 & 0.307 & 0.037 & 79 \\
\hline $01 \mathrm{HCl}$ & 620 & 0.313 & 0.276 & 0.037 & 58 \\
\hline 005HCl-RT & 650 & 0.328 & 0.291 & 0.037 & 56 \\
\hline 005EDTA & 701 & 0.372 & 0.282 & 0.090 & 121 \\
\hline
\end{tabular}

\section{Water sorption properties}

The hydrophilicity of any sorbent is quantitatively and qualitatively classified based on the type of the sorption isotherms. ${ }^{5}$ Fig. 4 shows the water isotherms of the parent and modified samples measured at $25{ }^{\circ} \mathrm{C}$. The water isotherm of the parent sample exhibits a type I isotherm, which is typical of very hydrophilic zeolites. The type I isotherm indicates materials with a high water sorption capacity and a very fast reaction saturation at a low partial pressure $\left(p / p_{0}\right)$, followed by consistent adsorption over a wide range of $p / p_{0}$ due to water saturation in the pores. These sorbents are classified as very hydrophilic due to their high affinity to water even at low $p / p_{0}$.

The samples treated with the diluted solutions of $\mathrm{HCl}$ (0.025 M, 0.05 M, and 0.1 M) showed higher water uptakes than the parent sample, most probably due to the defects in the framework, which were created in the framework after the opening of the Si-O-Al bonds, which is a known effect of the mild acid treatment. ${ }^{23}$ The generation of additional binding sites (e.g. framework defects) for water molecules influenced the increase of water uptake (see Tables 2 and 3).

Besides this effect, the introduction of mesopores into the materials can facilitate the access to active sites of the material. ${ }^{37}$ The shape of the isotherm of the 005EDTA sample was changed at a low partial pressure (up to $0.15 p / p_{0}$ ), indicating a weaker hydrophilic character of this sample in this range of

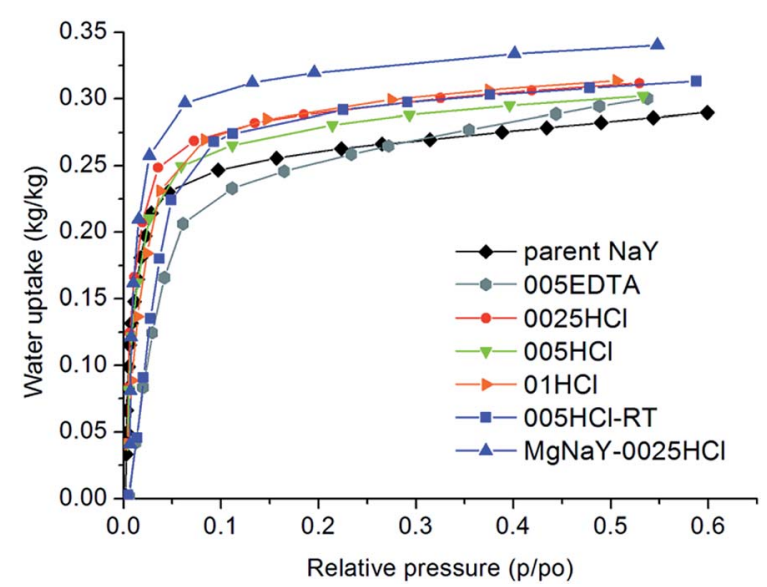

Fig. 4 Water uptake at $25{ }^{\circ} \mathrm{C}$ of the parent sample $\mathrm{NaY}$ and the modified samples. relative pressures and consequently a lower desorption temperature, while the formation of mesopores after $\mathrm{Al}$ extraction increased the water uptake at relative pressures above 0.35 $p / p_{0}$ (Fig. 4). ${ }^{37}$ A similar isotherm shape with a less steep uptake at very low relative pressure is also evident for the sample treated in $0.05 \mathrm{M} \mathrm{HCl}$ at room temperature for a longer time $(120 \mathrm{~h})$ due to its lower crystallinity. The highest water uptake was observed for the Mg-exchanged acid-treated sample due to the presence of smaller $\mathrm{Mg}$ cations, which increased the pore volume of the sample ${ }^{8}$ (see Table 2).

The isobars of all samples were measured up to a temperature of $150{ }^{\circ} \mathrm{C}$ for evaluating their water loading spread and for calculating their adsorption enthalpies. The isobars were measured using the Rubotherm balance and are shown in Fig. 5.

For comparison, the isobar of zeolite NaMSX is plotted too. The highest uptake over the entire temperature range was identified for the MgNaY-0025 $\mathrm{HCl}$ sample, which also shows higher water loading after desorption. The 005EDTA sample shows a weaker hydrophilic behaviour, e.g. the lowest loading at the highest temperature, but also the lowest uptake (besides the NaMSX) for the lowest temperature, due to its higher Si/Al molar

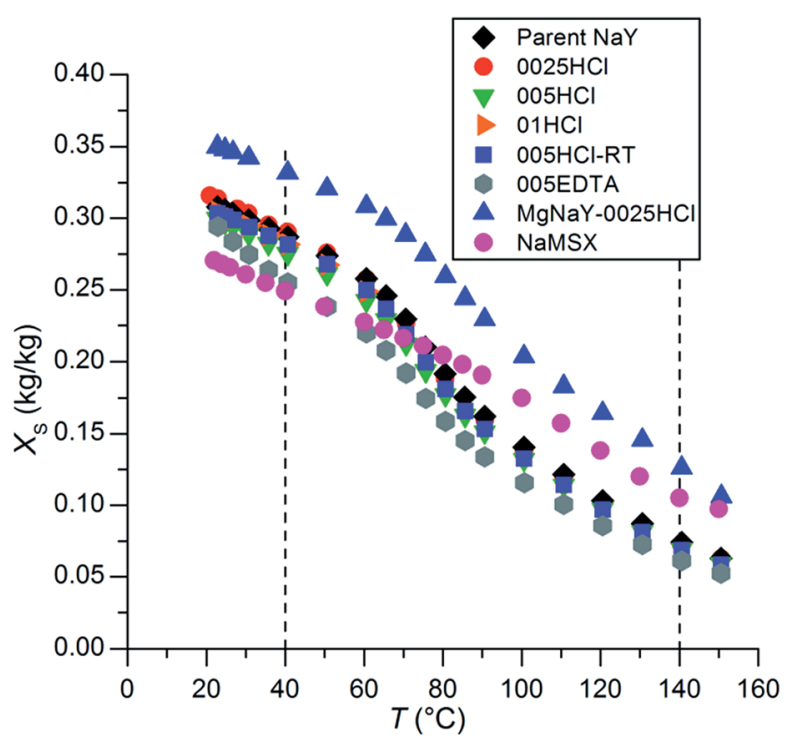

Fig. 5 Water adsorption isobars at $1.23 \mathrm{kPa}$ of the parent $\mathrm{NaY}$, the modified samples and NaMSX. 
ratio. The water uptake values of the other modified samples and the parent sample are close to each other, but differ considerably from the values of the NaMSX. The XRD pattern (Fig. S5 $\dagger$ ), SEM picture (Fig. S6 $\dagger$ ), water adsorption isotherm (Fig. S7†) and textural properties (Table S2 $\dagger$ ) of the NaMSX material can be found in the ESI. $\dagger$ The NaMSX shows a lower water uptake at low temperatures and higher water uptake at high temperatures. The former can also be explained by the presence of the binder in the NaMSX with an amount of $18 \%$, which does not contribute to the water adsorption. ${ }^{11}$ The latter is due to the lower $\mathrm{Si} / \mathrm{Al}$ molar ratio with a value of about $1.2 \mathrm{in}$ comparison to the NaY samples. These adsorption characteristics result in a lower water loading spread in comparison to the NaY samples.

For calculating the heat of adsorption by using the theory of Dubinin, each isobar has to be transformed into the characteristic curve, which shows the adsorbed volume $W_{\text {ads }}$ as a function of the adsorption potential $\Delta F$. The characteristic curve of each sample is plotted in Fig. 6 . These curves are very similar to the isobars in Fig. 5, since eqn (1) and (2), which are used for the transformation, include the water uptake and temperature, respectively.

The differential enthalpy of adsorption $\Delta h_{\mathrm{ads}}$ as a function of the water uptake $X_{\mathrm{S}}$ was calculated for all the samples using eqn (4) and is plotted in Fig. 7.

It is well known that the adsorbents with low water uptake after desorption and high water uptake after adsorption, resulting in high water loading spread $\Delta X_{S}$ to reach high storage densities, are needed for sorption heat storage. ${ }^{4}$ The quantities of the integral heat of adsorption $q_{\text {ads }}$ for each sample were calculated using the procedure and under the working conditions described in the Water sorption characterization section. The heat of vaporization $\Delta h_{\mathrm{v}}$ has been calculated at an adsorption temperature of $40{ }^{\circ} \mathrm{C}$. The value of $X_{\mathrm{S} \text {,des }}$ corresponds to the water uptake at equilibrium after desorption at

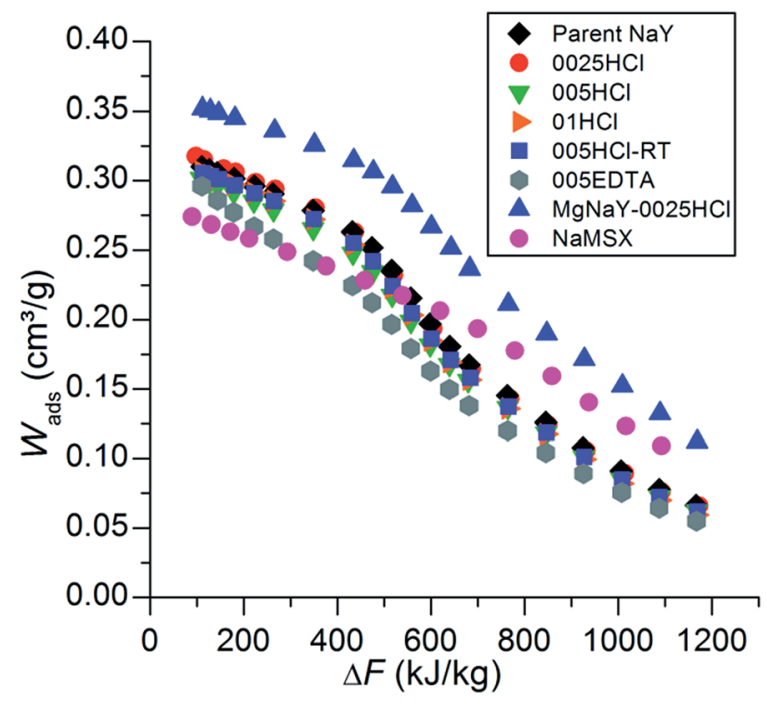

Fig. 6 The characteristic curves of the parent $\mathrm{NaY}$, the modified samples and NaMSX. These curves are determined from the water adsorption isobars of Fig. 5 using eqn (1) and (2).

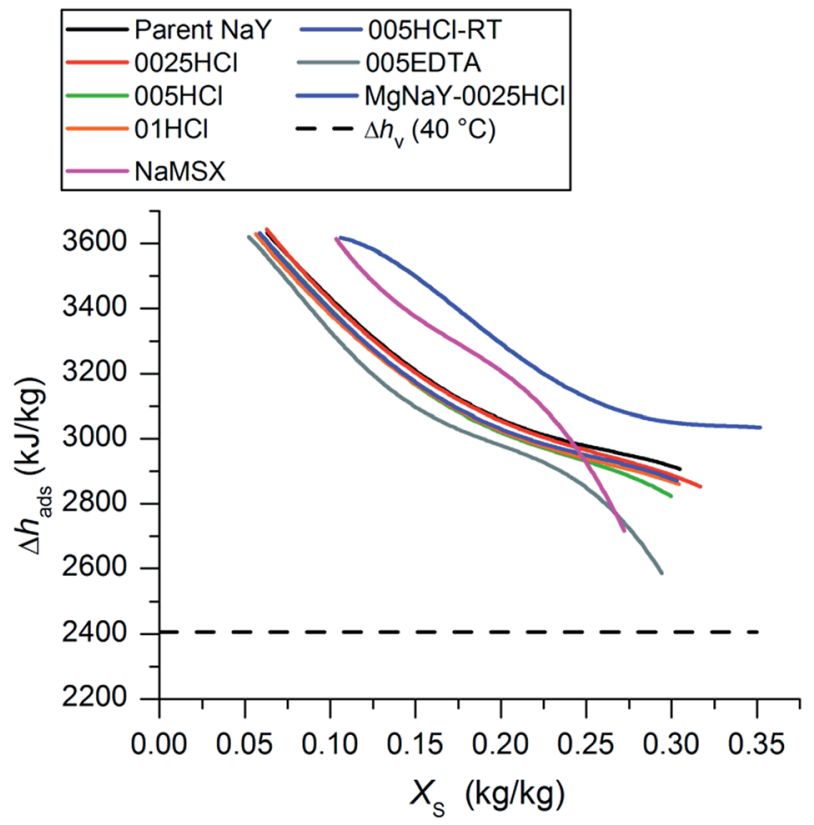

Fig. 7 Differential enthalpy of adsorption $\Delta h_{\text {ads }}$ as a function of the water uptake of the samples $X_{\mathrm{S}}$. The heat of evaporation has been evaluated at an adsorption temperature of $40^{\circ} \mathrm{C}$.

$140{ }^{\circ} \mathrm{C}$ and $1.23 \mathrm{kPa}$ and the value of $X_{\mathrm{S} \text {,ads }}$ corresponds to the water uptake after adsorption at $40{ }^{\circ} \mathrm{C}$ and $1.23 \mathrm{kPa}$. The results are listed in Table 4 . The highest $q_{\text {ads }}$ was evaluated for the $0025 \mathrm{HCl}$ sample with a value of $187.9 \mathrm{~W} \mathrm{~h} \mathrm{~kg}^{-1}$. This value is slightly above the values of the parent sample (185.0 $\left.\mathrm{W} \mathrm{h} \mathrm{kg}^{-1}\right)$, the $01 \mathrm{HCl}$ sample $\left(185.3 \mathrm{~W} \mathrm{~h} \mathrm{~kg}^{-1}\right.$ ) and the $005 \mathrm{HCl}-\mathrm{RT}$ sample (183.3 $\mathrm{W} \mathrm{h} \mathrm{kg}^{-1}$ ). Although MgNaY-0025HCl has the highest water uptake after adsorption $\left(0.3336 \mathrm{~kg} \mathrm{~kg}^{-1}\right)$, the integral heat of adsorption was determined to be $179.4 \mathrm{~W} \mathrm{~h} \mathrm{~kg}^{-1}$ and thus below those of the previously mentioned samples. To explain these results, the water loading spreads $\Delta X_{\mathrm{S}}$ of the samples had to be compared, which are shown in Table 4 , too.

The loading spread of the MgNaY-0025 HCl sample is, with a value of $0.2005 \mathrm{~kg} \mathrm{~kg}^{-1}$, less than the values of the previously mentioned samples, because the water uptake after desorption $\left(140{ }^{\circ} \mathrm{C}\right.$ and $\left.1.23 \mathrm{kPa}\right)$ is almost twice as much as the water uptake of the other samples. This is due to the presence of $\mathrm{Mg}$ cations in the $\mathrm{MgNaY}-0025 \mathrm{HCl}$ sample, which influence the increase in the desorption temperature. The desorption temperature of $140{ }^{\circ} \mathrm{C}$ was too low to remove water from the $\mathrm{Mg}$ adsorption sites, which is in agreement with our previous result (see Table 2). The samples 005EDTA and $005 \mathrm{HCl}$ show the lowest energy storages densities with values of $166.1 \mathrm{~W} \mathrm{~h} \mathrm{~kg}$ and $177.4 \mathrm{~W} \mathrm{~h} \mathrm{~kg}^{-1}$, respectively. However, their energy storage densities are still above the energy storage density of NaMSX with a value of $127 \mathrm{~W} \mathrm{~h} \mathrm{~kg}^{-1}$. As a result, an increase in storage density of about $40 \%$ can be stated using the $0025 \mathrm{HCl} \mathrm{NaY}$ sample instead of the NaMSX. Therefore, it can be concluded that a binder-free NaY zeolite and samples treated with $\mathrm{HCl}$ and $\mathrm{H}_{4}$ EDTA have a significant advantage in comparison to the used NaMSX type, regarding the storage density at a charging temperature below $140{ }^{\circ} \mathrm{C}$. 


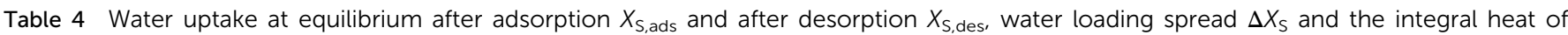
adsorption $q_{\text {ads }}$ in $\mathrm{kJ} \mathrm{kg}^{-1}$ and $\mathrm{W} \mathrm{h} \mathrm{kg}^{-1}$ for each sample

\begin{tabular}{llllll}
\hline Sample & $X_{\mathrm{S}, \text { ads }}\left(\mathrm{kg} \mathrm{kg}^{-1}\right)$ & $X_{\mathrm{S}, \mathrm{des}}\left(\mathrm{kg} \mathrm{kg}^{-1}\right)$ & $\Delta X_{\mathrm{S}}\left(\mathrm{kg} \mathrm{kg}^{-1}\right)$ & $q_{\mathrm{ads}}\left(\mathrm{kJ} \mathrm{kg}^{-1}\right)$ & $q_{\mathrm{ads}}(\mathrm{W} \mathrm{h} \mathrm{kg})$ \\
\hline Parent NaY & 0.2898 & 0.0783 & 0.2115 & 666.1 & 187.0 \\
0025HCl & 0.2931 & 0.0776 & 0.2155 & 638.7 & 187.9 \\
005HCl & 0.2775 & 0.0735 & 0.2040 & 666.9 & 177.4 \\
01HCl & 0.2833 & 0.0703 & 0.2130 & 659.8 & 185.3 \\
005HCl-RT & 0.2836 & 0.0730 & 0.2106 & 597.9 & 183.3 \\
005EDTA & 0.2573 & 0.0653 & 0.1920 & 646.0 & 166.1 \\
MgNaY-0025HCl & 0.3336 & 0.1331 & 0.2005 & 457.3 & 179.4
\end{tabular}

The adsorption/desorption cycling stability of the parent $\mathrm{NaY}, 0025 \mathrm{HCl}, 005 \mathrm{EDTA}$ and MgNaY-0025HCl samples has been evaluated according to the stability test conditions (see the Experimental section). All the modified samples showed good hydrothermal stability. After 20 cycles, the percentage reduction of the water uptake of the parent zeolite, MgNaY-0025 HCl and 005EDTA, measured at $40{ }^{\circ} \mathrm{C}$ and $1.23 \mathrm{kPa}$, is less than $2 \%$. The $0025 \mathrm{HCl}$ sample shows a slightly higher decrease with a water uptake reduction percentage of $6 \%$ compared to the initial water uptake. The structural properties of these samples after 20 cycles between temperatures of $140{ }^{\circ} \mathrm{C}$ and $40{ }^{\circ} \mathrm{C}$ under a water vapour pressure of $1.23 \mathrm{kPa}$ were determined. The XRD pattern (Fig. 8) shows highly crystalline samples.

In the XRD pattern of the $0025 \mathrm{HCl}$ sample an additional minor crystalline phase was observed, which can have an influence on lower water uptake. The SEM pictures (Fig. S2†) indicated no fragmentation of crystals, neither considerable changes in the zeolite morphology. Minor crystallinity loss (59\%) (Table 5) was observed for the parent $\mathrm{NaY}$ and modified samples after 20 cycles of adsorption and desorption, showing good hydrothermal stability of these samples under specific adsorption storage conditions.

A slight decrease in the Si/Al molar ratio was determined for the parent $\mathrm{NaY}, 0025 \mathrm{HCl}$ and $\mathrm{MgNaY}-0025 \mathrm{HCl}$ samples, while a significant decrease was found for the 005EDTA sample. During the cycling test acid hydrolysis can occur, which is

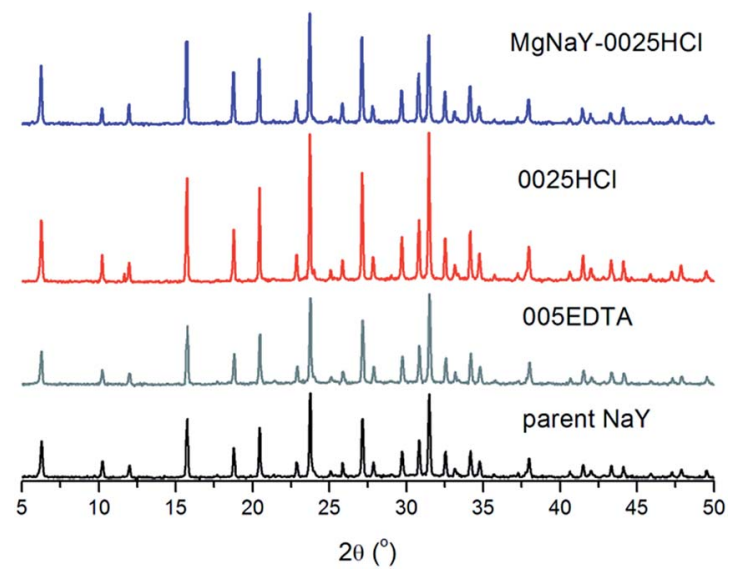

Fig. 8 XRD pattern of the samples after 20 cycles between temperatures of $140{ }^{\circ} \mathrm{C}$ and $40^{\circ} \mathrm{C}$ under a water vapour pressure of $1.23 \mathrm{kPa}$. typical for Al-rich zeolites, where $\mathrm{Si}$ and $\mathrm{Al}$ can be removed from the framework. ${ }^{20,34}$ Amorphous materials such as silica gels, kaolinite or sodium aluminosilicate were reported by several authors, ${ }^{38}$ which can be removed during the cycling test, leading to a lower Si content in the sample and decreasing Si/Al molar ratio. The decrease in the BET specific surface area, micropore volume and total pore volume was observed for all samples after 20 cycles of adsorption/desorption (Fig. S3, $\uparrow$ Table 5) due to minor structure decomposition and the formation of amorphous non-porous materials containing $\mathrm{Al}$ and $\mathrm{Si}$ species. ${ }^{19,20}$ For example, the 005EDTA sample shows the largest degree of amorphization, which can be related to a lower external surface area as well as lower mesopore volume. ${ }^{38}$ Furthermore, the BET specific surface area of the $0025 \mathrm{HCl}$ sample was decreased significantly, probably due to the presence of the nonporous material, which can be related to the highest reduction percentage of water uptake after 20 cycles. $^{38}$ The water isotherms of these samples measured at $25{ }^{\circ} \mathrm{C}$ (Fig. S4 $\dagger$ ) still exhibit a type I isotherm, indicating the preservation of the hydrophilicity of the materials.

The kinetic uptake curves of the parent $\mathrm{NaY}, 0025 \mathrm{HCl}$, 005EDTA and MgNaY-0025 HCl are plotted in Fig. 9. The MgNaY-0025HCl sample not only shows the highest but also the fastest absolute uptake due to its $\mathrm{Mg}$ cations, which generate a larger pore volume in the sample. ${ }^{9}$ After $20 \mathrm{~min}$, this sample had already adsorbed about $24 \%$ more water than the other three samples $\left(0.238 \mathrm{~kg} \mathrm{~kg}^{-1}\right.$ in comparison to approx. $0.192 \mathrm{~kg} \mathrm{~kg}^{-1}$ ). The faster adsorption kinetics of the MgNaY$0025 \mathrm{HCl}$ sample could be advantageous in applications with shorter adsorption/desorption cycle times. The kinetic uptake curves of the parent, the $0025 \mathrm{HCl}$ and the 005EDTA sample are close to each other.

Table 5 Relative crystallinity and Si/Al molar ratio of the parent $\mathrm{NaY}$ and modified samples after 20 cycles of adsorption and desorption between temperatures of $140{ }^{\circ} \mathrm{C}$ and $40{ }^{\circ} \mathrm{C}$ under a water vapour pressure of $1.23 \mathrm{kPa}$

\begin{tabular}{lll}
\hline Samples & $\begin{array}{l}\text { Relative crystallinity } \\
(\%)\end{array}$ & $\begin{array}{l}\text { Si/Al molar } \\
\text { ratio }\end{array}$ \\
\hline Parent NaY & 94 & 2.8 \\
0025HCl & 95 & 2.8 \\
005EDTA & 91 & 3.6 \\
MgNaY-0025HCl & 95 & 2.8
\end{tabular}




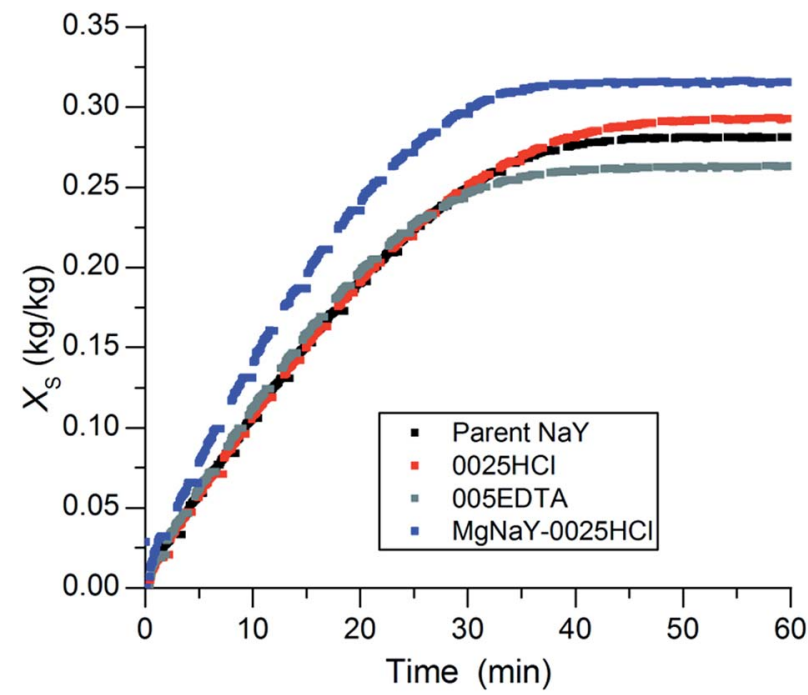

Fig. 9 Kinetic uptake curves of the parent NaY sample, the $0025 \mathrm{HCl}$ sample, the 005EDTA sample and the MgNaY-0025 HCl sample.

\section{Heat storage density in a mobile sorption heat storage system}

Since the working conditions (charging/discharging temperature and water vapour pressure) of the mobile sorption heat storage system differ slightly from the basic charging temperature scenario: $140{ }^{\circ} \mathrm{C}$, charging water vapour pressure: 1.23 $\mathrm{kPa}$, discharging temperature: $40{ }^{\circ} \mathrm{C}$ and discharging water vapour pressure: $1.23 \mathrm{kPa}$, the performance of the NaY samples in comparison to the NaMSX has been evaluated considering the mobile sorption storage working conditions. Krönauer et al. stated the energy storage density of the used NaMSX zeolite with a value of $143 \mathrm{~W} \mathrm{~h} \mathrm{~kg}^{-1}$ under the following working conditions of storage: charging temperature: $135^{\circ} \mathrm{C}$, charging water vapour pressure: $1.23 \mathrm{kPa}$, discharging temperature: $55{ }^{\circ} \mathrm{C}$ and discharging water vapour pressure: $5.63 \mathrm{kPa} .{ }^{25}$ By assuming the same working conditions and using the differential enthalpy curve of the parent $\mathrm{NaY}$ and the $0025 \mathrm{HCl}$ from Fig. 7, the energy storage density of $184.8 \mathrm{~W} \mathrm{~h} \mathrm{~kg}^{-1}$ and $188.7 \mathrm{~W} \mathrm{~h} \mathrm{~kg}^{-1}$ was calculated, respectively. Consequently, an increase in storage density of about $32 \%$ is possible by using the NaY zeolite. Interestingly, the storage densities of the $\mathrm{NaY}$ and modified samples are very close to the values calculated for the basic scenario. This can be explained by two facts that compensate one another. The higher water vapour pressure during adsorption leads to higher water uptakes and should lead to higher temperatures of adsorption. This advantage is almost eliminated by a reduced heat of vaporization at a temperature of $55{ }^{\circ} \mathrm{C}$ in contrast to the $40{ }^{\circ} \mathrm{C}$ of the basic scenario.

\section{Conclusions}

We demonstrated that the commercial granulated binder-free NaY zeolite can be used as the adsorbent in a mobile sorption storage system to recover industrial waste heat at a temperature level below $140{ }^{\circ} \mathrm{C}$. The aim of our study was to decrease the desorption temperature of granulated binder-free NaY zeolites by changing their hydrophilic properties and to preserve high energy storage densities. The performance of adsorbents in sorption heat storage depends on the type of post-synthesis treatment. Post-synthesis modifications using mild $\mathrm{HCl}$ treatment and chemical treatment with $\mathrm{H}_{4}$ EDTA (one step) lead to a reduction in the desorption temperature ranging from 10 to $30{ }^{\circ} \mathrm{C}$. On the other hand, a two-step procedure with sequential Mg-exchanged acid treatment can bring about enhanced water sorption capacity and desorption temperature. The $\mathrm{H}_{4}$ DTA treatment improved the pore accessibility by removal of $\mathrm{Al}$ from the framework. The mild acid treatment caused the generation of defects, which served as the binding sites for water, and thus the water uptake was increased. All these modifications were nondestructive, resulting in granulated products with good crystallinity. The repeated cycling stability of the parent NaY and modified samples $(0025 \mathrm{HCl}, 005 \mathrm{EDTA}$ and MgNaY$0025 \mathrm{HCl}$ ) was evaluated, showing comparatively good hydrothermally stability after 20 cycles between temperatures of $140{ }^{\circ} \mathrm{C}$ and $40^{\circ} \mathrm{C}$ under a water vapour pressure of $1.23 \mathrm{kPa}$. The evaluated energy storage densities of the parent $\mathrm{NaY}$ and the modified samples are up to $40 \%$ above the value of the $\mathrm{NaX}$ zeolite, which has been used in mobile sorption storage, at a desorption temperature of $140{ }^{\circ} \mathrm{C}$. The highest storage density was determined for the $0025 \mathrm{HCl}$ sample. Thus, from these results we can conclude that the use of NaY zeolite could be beneficial for low-temperature industrial waste heat recovery.

\section{Conflicts of interest}

There are no conflicts to declare.

\section{Acknowledgements}

Financial support from the Slovenian Research Agency through research programme P1-0021 (Nanoporous materials) and research project L1-7665 (Advanced heat storage materials for integrated storage solutions) is acknowledged. We thank CWK for supplying the granulated binder-free NaY and NaMSX zeolites. We thank Edi Kranjc for XRD measurements, Mojca Opresnik for EDX and nitrogen physisorption measurements, Dr Oleksii Pliekhov for water adsorption measurements and Dr Matjaž Mazaj for SEM pictures.

\section{References}

1 J. Lizana, R. Chacartegui, A. Barrios-Padura and C. Ortiz, Renewable Sustainable Energy Rev., 2018, 82, 3705-3749.

2 L. Scapino, H. A. Zondag, J. Van Bael, J. Diriken and C. C. M. Rindt, Renewable Sustainable Energy Rev., 2017, 76, 1314-1331.

3 A. Hauer, Adsorption, 2007, 13, 399-405.

4 S. K. Henninger, S. J. Ernst, L. Gordeeva, P. Bendix, D. Fröhlich, A. D. Grekova, L. Bonaccorsi, Y. Aristov and J. Jänchen, Renewable Energy, 2017, 110, 59-68.

5 A. Krajnc, J. Varlec, M. Mazaj, A. Ristić, N. Zabukovec Logar and G. Mali, Adv. Energy Mater., 2017, 7, 201601815; A. Ristić, 
N. Zabukovec Logar, S. K. Henninger and V. Kaučič, Adv. Funct. Mater., 2012, 22, 1952-1957.

6 E. P. Ng and S. Mintova, Microporous Mesoporous Mater., 2008, 114, 1-26.

7 I. A. Beta, H. Böhlig and B. Hunger, Phys. Chem. Chem. Phys., 2004, 6, 1975-1981.

8 J. Jänchen, D. Ackermann, H. Stach and W. Brösicke, Sol. Energy, 2004, 76, 339-344.

9 X. Li, S. Narayanan, V. K. Michaelis, Ta-C. Ong, E. G. Keeler, H. Kim, I. S. McKay, R. G. Griffin and E. N. Wang, Microporous Mesoporous Mater., 2015, 201, 151-159.

10 H. Stach, J. Mugele, J. Jänchen and E. Weiler, Adsorption, 2005, 11, 393-404.

11 K. Schumann, B. Unger, A. Brandt and F. Scheffler, Microporous Mesoporous Mater., 2012, 154, 119-123.

12 J. Jänchen, K. Schumann, E. Thrun, A. Brandt, B. Unger and U. Hellwig, Int. J. Low-Carbon Technol., 2012, 7, 275-279.

13 V. Valtchev, G. Majano, S. Mintova and J. Pérez-Ramírez, Chem. Soc. Rev., 2013, 42, 263-290; D. Verboekend, N. Nuttens, R. Locus, J. Van Aelst, P. Verolme, J. C. Groen, J. Pérez-Ramírez and B. F. Sels, Chem. Soc. Rev., 2016, 45, 3331-3352.

14 L. Bonaccorsi, P. Bruzzaniti, L. Calabrese and E. Proverbio, Microporous Mesoporous Mater., 2016, 234, 113-119.

15 T. H. Herzog, J. Jänchen, E. M. Kontogeorgopoulos and W. Lutz, Energy Procedia, 2014, 48, 380-383; W. Lutz, Adv. Mater. Sci. Eng., 2014, 724248.

16 E. F. T. Lee and L. V. C. Rees, J. Chem. Soc., Faraday Trans. 1, 1987, 83, 1531-1537.

17 M. B. Yue, T. Xue, W. Q. Jiao, Y. M. Wang and M.-Y. He, Microporous Mesoporous Mater., 2012, 159, 50-56.

18 G. T. Kerr, J. Phys. Chem., 1968, 72, 2594-2596.

19 M. C. Silaghi, C. Chizallet and P. Raybaud, Microporous Mesoporous Mater., 2014, 191, 82-96.

20 W. Lutz, H. Toufar, R. Kurzhals and M. M. Suckow, Adsorption, 2005, 11, 405-413.

21 J. Jänchen and H. Stach, Energy Procedia, 2012, 30, 289-293.

22 J. G. Martinez and K. Li, Mesoporous Zeolites: Preparation, Characterization and Applications, Wiley-VCH, 2015, pp. 321-348.
23 A. Sachse, A. Grau-Atienza, E. O. Jardim, N. Linares, M. Thommes and J. García-Martínez, Cryst. Growth Des., 2017, 17, 4289-4305.

24 L. Miró, J. Gasia and L. F. Cabeza, Appl. Energy, 2016, 179, 284-301.

25 A. Krönauer, E. Lävemann and A. Hauer, The 12th International Conference on Energy Storage, Innostock Conference, Lleida, Spain, 2012.

26 N. Yu, R. Z. Wang and L. W. Wang, Prog. Energy Combust. Sci., 2013, 39, 489-514.

27 Standard Test Method for Determination of Relative X-ray Diffraction Intensities of Faujasite-type Zeolite-containing Materials ASTM D3906-03, 2013.

28 ISO 9277, Determination of the Specific Surface Area of Solids by Gas Adsorption - BET Method, 2010.

29 B. Lippens and J. de Boer, J. Catal., 1965, 4, 319-323.

30 B. P. Bering, M. M. Dubinin and V. V. Serpinsky, J. Colloid Interface Sci., 1966, 21, 378-393.

31 Ch. Lehmann, S. Beckert, R. Gläser, O. Kolditz and T. Nagel, Appl. Energy, 2017, 185, 1965-1970.

32 D. Verboekend, G. Vilé and J. Pérez-Ramírez, Adv. Funct. Mater., 2012, 22, 916-928.

33 J. Richter-Mendau, W. Lutz and A. Grossmann, Cryst. Res. Technol., 1988, 23, 1245-1252.

34 W. Lutz, H. Toufar, D. Heidemann, N. Salman, C. H. Ruscher, T. M. Gesing, J. C. Buhl and R. Bertram, Microporous Mesoporous Mater., 2007, 104, 171-178; R. Dimitrijevic, W. Lutz and A. Ritzmann, J. Phys. Chem. Solids, 2006, 67, 1741-1748; F. Fischer, W. Lutz, J. C. Buhl and E. Laevemann, Microporous Mesoporous Mater., 2018, 262, 258-268.

35 Z. Qin, J. P. Gilson and V. Valtchev, Curr. Opin. Chem. Eng., 2015, 8, 1-6.

36 J. Aguado, D. P. Serrano, J. M. Escola and J. M. Rodríguez, Microporous Mesoporous Mater., 2004, 75, 41-49.

37 C. Gunathilake and M. Jaroniec, J. Mater. Chem. A, 2016, 4, 10914-10924.

38 N. Salman, C. H. Rüscher, J. C. Buhl, W. Lutz, H. Toufar and M. Stöker, Microporous Mesoporous Mater., 2006, 90, 339346. 